\title{
Influential Factors of Tourists' Word of Mouth in Low-carbon Eco-tourism Scenic Spots-A Case Study of Xingwen Shihai
}

\author{
Tingting Liu ${ }^{1, ~ a}$, Yuyan Luo ${ }^{1,2, b, ~ *, ~ Y o n g ~ Q i n ", ~ c, ~ X i n r a n ~ Y u, ~ d, ~ a n d ~ Z e r u i ~ S u ~}{ }^{1, e}$ \\ ${ }^{1}$ College of Management Science, Chengdu University of Technology, Chengdu 610059, China; \\ ${ }^{2}$ Post-doctorate $R$ \& D Base of Management Science and Engineering, Chengdu University of \\ Technology, Chengdu 610059, China.

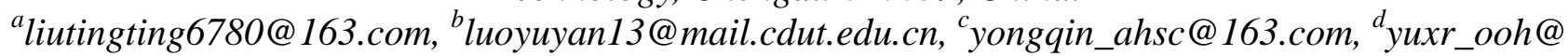 \\ 163.com, ${ }^{e}$ Zoeee_98@163.com \\ *corresponding author
}

Keywords: low-carbon eco-tourism, tourists' word of mouth, influential factors, Xingwen Shihai.

Abstract: With the rapid development of tourism, excessive carbon dioxide emissions and damaged environment, how to promote the low-carbon ecological development and economic development of scenic spots has become the highest priority at present. In order to explore the influential factors of tourists' word of mouth in low-carbon eco-tourism scenic spots, a questionnaire survey was conducted among 650 tourists in Xingwen Shihai scenic spot on word of mouth and the model was built. The data and models we used were validated and analyzed through SPSS22.0 and SmartPls3.0. It shows that the path coefficient of tourists' need satisfaction at basic level to the development level is 0.276 , which positively affects tourists' satisfaction at development level; the path coefficient of tourists' need satisfaction at basic level to their low-carbon ecotourism experience is 0.151 , which positively affects tourists' low-carbon ecotourism experience; the path coefficient of tourists' need satisfaction at development level to their low-carbon ecotourism experience is 0.618 , which significantly and positively affects tourists' low-carbon ecotourism experience; the path coefficient of tourists' low-carbon eco-tourism experience on tourists' word of mouth is 0.907 , which has a significant and positive effect on tourists' word of mouth.

\section{Introduction}

It is widely believed that excessive carbon dioxide emissions are likely to bring global climate change [1-3]. To curb this tendency, China announced that its carbon intensity would be reduced from 40 percent to 45 percent by 2020 (compared with the year of 2005) at the conference in Copenhagen, Paris. Besides, its carbon intensity can be expected to be reduced by 60 to 65 percent by 2010 (compared with the year of 2005). At that time, its carbon intensity will reach the peak. China is currently seeking for approaches to peak the carbon emissions as soon as possible. Beside some major energy sectors, tourism, as an important emitter of carbon dioxide, has become a vital driver of carbon reduction [4]. Now, low-carbon eco-tourism has become a global hot spot of 
tourism due to its low energy consumption and low pollution.

Tang and Zhong et al. discussed the developing strategy of low-carbon tourism in scenic spots from the four main core stakeholders of scenic spots: government departments, tourist destinations, tourism enterprises and tourists. It's believed that tourists are important in the low-carbon development of scenic spots [5]. Wu and other scholars hold that once the tourists enter the scenic spots, a subject-object relation can be produced, in which the scenic spots are the subject and the tourists are the object. In this condition, tourists' word of mouth is defined as the quality evaluation of subject-object relation between tourists and the scenic spots produced in tourists' sightseeing [6]. that is, one of the cores in scenic spots' image building is the tourists' revisit and their tendency of recommending the scenic spot to others and putting forward their opinions word of mouth [7]. Usually, tourists' word of mouth can be influenced by the improvement of scenic spots' image and vice versa add to their further development [8].

At home and abroad, the scholars prefer taking tourists' word of mouth as the outcome variable to discuss its antecedent variables. Among the antecedent variables, there are three factors involved: the image of the destination, the satisfaction of tourists and the experience of tourists.

In the study of how tourists' word of mouth are affected by the image of destination, Zhang et al. found that the image of destination has dominant effects on tourists' word of mouth, but the effects differ in degree. The overall image of destination has the biggest impact on tourists' word of mouth loyalty, followed by emotional image and cognitive image [9]. Through the questionnaire survey analysis of the tourists in Fenghuang ancient city, it can be found that the image of the destination positively influences the tourists' intention of revisiting, but it is mainly affected by the emotional image [10]. On the contrary, compared with the relationship between the image of destination and comprehensive loyalty, that between the image of destination and behavioral loyalty is even weaker [11].

In the study of the impact tourists' satisfaction has on tourists' word of mouth, Sangjae et al. analyzed the cases of Chinese tourists bounding to South Korea and found that factors such as tourists' expectation, tourists' motivation, tourism quality and tourists' satisfaction all had effects on tourists' word of mouth [8]. Through the study of Athens scenic spot, scholars Frangos et al. found that factors such as tourists' price satisfaction, natural environment and historical sites had great statistical significance on tourists' word of mouth [12]. Wu, a domestic scholar, held an exploration of the key factors influencing tourists' word of mouth loyalty by conducting a survey on tourists visiting Dalian, and believed that it was crucial to motivate tourists' high opinion loyalty to the scenic spot and improve their satisfaction [6]. According to Chen's research, when customers have a high sense of satisfaction, their evaluation of goods is also improved, and customer satisfaction has a significant positive effect on their opinion loyalty [13].

In the research of the impact tourists' experience has on tourists' word of mouth, Wijaya and other scholars found that through the study on international tourists of their dining process (before, during and after meals) and found that tourists' dining experience has effects on their overall dining satisfaction and their future behavioral intention [14]. Pearce explored the tourists' experience and overall satisfaction by measuring tourists' experience in parks, so as to measure tourists' word of mouth and offer suggestions and development strategies to the managers [15]. Chen and Guo, two domestic scholars, proposed that the tourists' experience has a significant positive influence on the consumption emotion, and the consumption emotion of tourists has a further significant influence on the public praise recommendation among citizens through the investigation and research on the tourist experience in Xiamen and Zhangzhou [16].

From the existing literatures, it can be found that the image of destination, the tourists' satisfaction and experience all have effects on tourists' word of mouth. In addition, in the research of low-carbon ecotourism or tourists' word of mouth, few scholars combined tourists' word of 
mouth with the development of low-carbon ecotourism in the scenic spots. As an essential part in the development of scenic spots, tourists' word of mouth plays a key role in the development of low-carbon eco-tourism in scenic spots as well. Originated from this idea, this paper starts from the theory of low-carbon ecotourism and tourists' behaviors, taking Xingwen Shihai as an example. Then, a model is built to explore and analyze the relations between tourists' satisfaction and their experience in low-carbon ecotourism scenic spots. Besides, the further influence tourists' experience has on tourists' word of mouth is also in discussion in this paper.

\section{The Literature Reviewed and the Hypothesis Postulated}

\subsection{Tourist Experience.}

As early as the early 21st century, some scholars put forward the concept of experience economy [17]. It is a new economic form following the agricultural economy, industrial economy and service economy. With their riching and diversifying experience in travel, the maturing tourism consumption and the increasing demand, tourists are no longer satisfied with the monotonous tourism products, pursuing personalized, experiential, emotional, recreational and beautified tourism experience in the era of experience economy.

Wijaya and other researchers have found that both internal and external factors such as food quality, food culture, personal experience and physical condition have effects on tourists' dining experience [14]. Cohen proposed that tourists can be classified according to their tourism experience and the various activities they experience represent different modes [18]. In the exploration of influential factors of tourists' experience degree, Chen concluded that the influential factors consist of tourists' behavior, the results, the environmental interference variables and other prior factors [19]. At home, professor Xie proposed the concept of tourism experience for the first time. He believed that tourists' experience is related to the tourism resources in the scenic spots, their participation in activities and the communication with others [20]. In the research of tourists' experience in Leshan, scholars such as Pan and Zhou found that the tourists' experience is related to their taking time in scenic sightseeing, subjective evaluation of learning experience, intuitive impression and the products they buy in the scenic spots [21].

\subsection{Tourists’ Satisfaction of Demand.}

In 1943, American psychologist Maslow proposed in his paper "theory of human motivation" that human needs are divided into five levels like a ladder from low to high: physiological needs, safety needs, social needs, respect needs and self-realization needs [22]. According to Maslow's theory of demand, this paper divides tourists' demand into basic level and development level of demand, including two aspects: eating, lodging and transporting; travelling, shopping and chilling out, among which the services provided by scenic spots differ in level.

As early as the 1980s, Pizam et al. studied the tourists' satisfaction with the coastal tourism destinations and believed that the tourists' satisfaction originates from the deviation of their expectations before entering the scenic spots and their experience after entering, that is, the satisfaction generated by their demands and the services provided by the scenic spots [23]. In the theme park visitors' satisfaction research, scholar Lian put forward measures of improving theme park visitors' satisfaction in the view of present status of tourists' satisfaction, such as tickets, commodity prices, reservation services and guidance. It can be found that the improvement of the signage facilities such as visible theme park facilities, commodity prices have relations with tourists' satisfaction [24]. In the tourism development study of hakka culture, three scholars, Yu, Feng and Liang, proposed that the image value, product value, environmental value and service value of 
hakka culture tourism all have an impact on the tourists’ satisfaction [25].

\subsection{Hypothesis Postulated.}

In this article, the two aspects (eating, lodging and transporting; travelling, shopping and chilling out) are divided into two dimensions: basic and demand development layer of tourists. Besides, the demand development layer of tourists is divided into four dimensions: the management of scenic spots, natural environment, entertainment and low-carbon operation. In Zhang's research of the relations between tourists' demand classification and their satisfaction, it's considered that tourists' demand at basic level has significant effects on tourist development demand satisfaction [26]. In order to explore the relations between tourists' satisfaction of basic and development demand so as to explore the key factors of effects, this paper proposes the research hypothesis as follows:

H1: tourists' satisfaction of basic demand positively influences their satisfaction of development demand.

In Wan's study of tourists' satisfaction in Kunming, she proposed that tourists' satisfaction has a direct positive effect on tourists' experience. She believed that tourists' experience is the main factor that has effects on tourists' satisfaction and tourists' personal experience in scenic spots is very important, which directly affects tourists' satisfaction [27]. Based on her hypothesis, this paper discusses the impact tourists' satisfaction has on tourists' experience in reverse and proposes the research hypothesis:

H2: tourists' satisfaction of basic demand positively influences tourists' experience of low-carbon eco-tourism.

H3: tourists' satisfaction of development demand positively influences tourists' experience of low-carbon eco-tourism.

In the study of tourists' word of mouth in Dalian, Wu analyzed the influential factors and mutual relations of tourists' word of mouth loyalty, and found that the tourists' experience has impacts on the quality of subject-object relationship, which indirectly affects the tourists' word of mouth loyalty. In the subject-object relationship, tourists' satisfaction has the greatest impact on tourists' loyalty [6]. Accordingly, this paper proposes the research hypothesis:

H4: the tourists' low-carbon eco-tourism experience positively influences tourists' word of mouth.

\section{Data and Method}

\subsection{Questionnaire Design and Data Collection.}

From July 15 to 19, 2018, the research group conducted an anonymous questionnaire survey on karst cave tourists in Xingwen Shihai scenic spot. 650 questionnaires were distributed and 645 questionnaires were recovered, with a recovery rate of 99.2\%. Eliminate invalid questionnaires and remain 635 valid questionnaires, the effective recovery rate was $97.6 \%$. The contents of the questionnaire are designed according to table 1 , including the basic demographic characteristics, the satisfaction degree of the elements of tourists' demand and the tourist experience. The latter adopts the Likert 5 scale. From very dissatisfied to very satisfied five yardsticks, scoring with 1 to 5 , the higher the score is, the higher the satisfaction evaluation value is, and the better the tourist experience is.

This study is to investigate and analyze the tourists' experience of low-carbon eco-tourism and the tourists' word of mouth in Xingwen Shihai scenic spot. By referring to a large number of mature scales of predecessors, based on relevant literature at home and abroad and combined with the purpose of this study, a preliminary questionnaire is formed. 
The questionnaire consists of three parts, which are the basic information of tourists, tourists' experience of various facilities in the scenic spot, and tourists' feedback and evaluation. The first part is the basic information of tourists, including gender, age, monthly income, job position and annual travel budget. The second part is tourists' experience of the basic facilities of the scenic spot. The third part is the tourists' satisfaction with the scenic spot and the follow-up behavioral intention survey, that is, whether they are willing to revisit, whether they are willing to recommend to their relatives and friends, and their comprehensive evaluation of the scenic spot.

According to the data analysis of Xingwen Shihai survey, the following results are obtained: in the questionnaire survey on the low-carbon eco-tourism experience of tourists in Xingwen Shihai scenic area, there are 277 males and 358 females, a ratio of male to female is about 8:10. The gender distribution is relatively consistent. Among them, the majority of them are younger, mainly under the age of 35. Most of the tourists' academic qualifications are undergraduate or below the level of college; As for the positions of tourists, most of them are students, followed by other occupations. In the survey of the purpose of low-carbon eco-tourism, the proportion of people who take leisure vacation and relax their mood is the largest, accounting for $81.2 \%$. The detailed results are shown in table 2 . In this survey, all the tourists are basically met.

Table 1 Factors influencing tourists' word of mouth in low-carbon eco-tourism scenic spots

\begin{tabular}{|c|c|c|c|}
\hline \multirow{8}{*}{$\begin{array}{l}\text { The satisfaction of } \\
\text { tourists' basic level } \\
\text { (N1) }\end{array}$} & \multirow{3}{*}{ Catering accommodation (RL) } & Serve & RL1 \\
\hline & & Environment & RL2 \\
\hline & & Publicity influence & RL3 \\
\hline & \multirow{5}{*}{ Transportation (S) } & The transfer locations are unified & S1 \\
\hline & & Vehicle capacity & $\mathrm{S} 2$ \\
\hline & & Reasonable signage setup & S3 \\
\hline & & Classification of parking lots & S4 \\
\hline & & Traffic order guidance & S5 \\
\hline \multirow{17}{*}{$\begin{array}{l}\text { The satisfaction of } \\
\text { tourists' development } \\
\text { level demand (N2) }\end{array}$} & \multirow{7}{*}{ Management (M) } & Supporting facility & M1 \\
\hline & & Waste gas and waste water treatment & M2 \\
\hline & & Security & M3 \\
\hline & & Informationalized level & M4 \\
\hline & & Propagandizing and popularizing & M5 \\
\hline & & Employee services & M6 \\
\hline & & Service quality of scenic spot & M7 \\
\hline & \multirow{2}{*}{ Entertainment (E) } & Low-carbon entertainment & E2 \\
\hline & & $\begin{array}{l}\text { The degree of combination of entertainment and local } \\
\text { folk culture features }\end{array}$ & E3 \\
\hline & \multirow{4}{*}{ Environment (EV) } & Water quality & EV1 \\
\hline & & Conservation of natural resources & EV2 \\
\hline & & Conservation of diversity of natural resources & EV3 \\
\hline & & Air quality & EV4 \\
\hline & \multirow{4}{*}{ Run (R) } & Low carbon publicity & $\mathrm{R} 1$ \\
\hline & & Development of the scenic spot & $\mathrm{R} 2$ \\
\hline & & The number of low-carbon eco-tourism products & R3 \\
\hline & & The number of low-carbon eco-tourism products & $\mathrm{R} 4$ \\
\hline $\begin{array}{l}\text { The tourists' } \\
\text { low-carbon } \\
\text { eco-tourism experience } \\
\text { (N3) }\end{array}$ & \multicolumn{2}{|l|}{ Satisfaction } & EX1 \\
\hline \multirow[b]{2}{*}{$\begin{array}{l}\text { The tourists' word of } \\
\text { mouth (N4) }\end{array}$} & \multicolumn{2}{|l|}{ Revisit } & EY \\
\hline & \multicolumn{2}{|l|}{ Recommend } & $\mathrm{TJ}$ \\
\hline
\end{tabular}


Table 2 Respondent profile

\begin{tabular}{|c|c|c|}
\hline Demographic variable & Item & Percentage \\
\hline \multirow{3}{*}{ Gender } & Male & 0.44 \\
\hline & Female & 0.56 \\
\hline & Under 18 & 0.25 \\
\hline \multirow{5}{*}{ Age } & $18-24$ & 0.24 \\
\hline & $25-34$ & 0.23 \\
\hline & $35-44$ & 0.18 \\
\hline & 45-65 & 0.09 \\
\hline & Above 66 & 0.008 \\
\hline \multirow{4}{*}{ Education level } & Junior secondary and below & 0.32 \\
\hline & High school/technical secondary school & 0.31 \\
\hline & Undergraduate/junior college & 0.34 \\
\hline & Graduate and above & 0.038 \\
\hline \multirow{6}{*}{ Profession } & Public officers (civil servants or staff of public institutions) & 0.1 \\
\hline & Enterprise personnel & 0.16 \\
\hline & Individual and private owners & 0.15 \\
\hline & Retiree & 0.03 \\
\hline & Student & 0.35 \\
\hline & Else & 0.22 \\
\hline \multirow{6}{*}{ Purpose } & Health, pension, physical fitness and other health tourism & 0.078 \\
\hline & Take a vacation and relax & 0.812 \\
\hline & Conference and exhibition, welfare tourism and other business tourism & 0.02 \\
\hline & Wedding, marriage, anniversary tourism, religious pilgrimage and other emotional tourism & 0.015 \\
\hline & Adventure & 0.104 \\
\hline & $\begin{array}{l}\text { Scientific investigation, training, development training, photography, wind, various } \\
\text { summer camps and other activities }\end{array}$ & 0.055 \\
\hline
\end{tabular}

\subsection{Data Reliability and Validity Test.}

Reliability test refers to the scale's consistency, which can be divided into internal reliability, retest reliability and duplicate reliability. This paper tests its internal reliability, that is, the scale's internal consistency. Validity test is the correctness of the scale, which is divided into content validity, convergent validity and discriminant validity. These three indicators are often used together. Content validity is to measure the item and quantity to be sufficient to represent the concept of measurement; the convergent validity refers to the higher correlation between different items of the same cross section. Discriminant validity means that the correlation of the items between different sections is low. To analyze the validity of the data collected from the questionnaire, that is, to test the extent to which the collected data reflect the objective reality. In this paper, using Cronbach's Alpha and structural validity test, the data collected in the questionnaire are imported into SPSS22.0 for reliability test, and the Cronbach's Alpha is $0.910>0$, 7. And the reliability of each latent variable is tested, the Cronbach's Alpha value and table 3 reliability test results show that the data collected by the questionnaire have good reliability, and all the latent variables and the overall data pass the reliability test.

KMO value and battle ball test were carried out on the data. In the process of validity test, variables that made the data unable to be validated were excluded one by one, and KMO value was $0.937>0.7$ and $p$ value was 0.000 . Obviously, the validity test is passed, and factor analysis can be carried out. In this paper, the principal component method is used to extract 6 common factors with characteristic values greater than 1 , whose variance contribution rate is $54.434 \%$, which can reflect a large part of the data of the sample. By means of the rotated composition matrix, the observed 
variables with a factor load of less than 0.5 for the common factor and a factor load of more than 0.5 for two or more common factors for the same observation variable were deleted.

Discriminant validity evaluation has become an accepted prerequisite for analyzing the relationship between potential variables. For the variables-based structural equation modeling, such as partial least squares, Fornell-Larcker criterion and the cross-load test are the main methods to evaluate the effectiveness of the evaluation. Simulation studies show that these methods cannot reliably detect the lack of identification effectiveness in common research situations. Henseler and Ringle scholars model developed heterogeneous-single characters (HTMT) ratio through the simulation, which can better detect the difference between the validity of latent variables. They suggest that heterogeneity correlations in a well-fitted model should be less than single-trait correlations, which means that the HTMT ratio should be less than 1.0, and that if the HTMT value is less than 0.9 , then the latent variables of the model will have different validity [28]. After the data were imported into SmartPls3.0 for the test of convergence validity and discriminant validity, table 4 was obtained. It can be seen from table 4 that the HTMT value of each potential variable was lower than 0.9 and the maximum value was 0.706 , and the validity of AVE $>0.5$ model of each potential variable was verified.

Table 3 Measurement model

\begin{tabular}{|c|c|c|c|}
\hline Latent variables & Observation variable & Factor loading & Cronbach's alpha \\
\hline \multirow{3}{*}{ RL } & RL1 & 0.838 & \multirow{3}{*}{0.702} \\
\hline & RL2 & 0.839 & \\
\hline & RL3 & 0.713 & \\
\hline \multirow{5}{*}{$\mathrm{S}$} & $\mathrm{S} 1$ & 0.718 & \multirow{5}{*}{0.785} \\
\hline & S2 & 0.647 & \\
\hline & S3 & 0.794 & \\
\hline & $\mathrm{S} 4$ & 0.786 & \\
\hline & S5 & 0.723 & \\
\hline \multirow{7}{*}{ M } & M1 & 0.64 & \multirow{7}{*}{0.854} \\
\hline & M2 & 0.716 & \\
\hline & M3 & 0.715 & \\
\hline & M4 & 0.733 & \\
\hline & M5 & 0.75 & \\
\hline & M6 & 0.773 & \\
\hline & M7 & 0.78 & \\
\hline \multirow{3}{*}{$\mathrm{E}$} & E1 & 0.866 & \multirow{3}{*}{0.799} \\
\hline & E2 & 0.879 & \\
\hline & E3 & 0.786 & \\
\hline \multirow{4}{*}{$\mathrm{EV}$} & EV1 & 0.707 & \multirow{4}{*}{0.757} \\
\hline & EV2 & 0.833 & \\
\hline & EV3 & 0.822 & \\
\hline & EV4 & 0.678 & \\
\hline \multirow{4}{*}{$\mathrm{R}$} & $\mathrm{R} 1$ & 0.673 & \multirow{4}{*}{0.745} \\
\hline & $\mathrm{R} 2$ & 0.716 & \\
\hline & R3 & 0.823 & \\
\hline & $\mathrm{R} 4$ & 0.796 & \\
\hline \multirow{2}{*}{ N1 } & RL & 0.855 & \multirow{2}{*}{0.807} \\
\hline & $\mathrm{S}$ & 0.855 & \\
\hline \multirow{4}{*}{ N2 } & M & 0.838 & \multirow{4}{*}{0.896} \\
\hline & $\mathrm{E}$ & 0.748 & \\
\hline & $\mathrm{EV}$ & 0.697 & \\
\hline & $\mathrm{R}$ & 0.816 & \\
\hline \multirow{2}{*}{ N3 } & EX1 & 0.909 & \multirow{2}{*}{0.791} \\
\hline & EX2 & 0.909 & \\
\hline \multirow{2}{*}{ N4 } & EY & 0.894 & \multirow{2}{*}{0.749} \\
\hline & $\mathrm{TJ}$ & 0.894 & \\
\hline
\end{tabular}


Table 4 Discriminant validity

\begin{tabular}{lllllll}
\hline & E & EV & M & R & RL & S \\
\hline E & 0.711 & & & & & \\
EV & 0.348 & 0.582 & & & & \\
M & 0.629 & 0.647 & 0.534 & & & \\
R & 0.706 & 0.568 & 0.675 & 0.569 & & \\
RL & 0.393 & 0.618 & 0.565 & 0.492 & 0.638 & 0.541 \\
S & 0.471 & 0.661 & 0.659 & 0.616 & 0.622 & \\
\hline
\end{tabular}

Note: the diagonals in the table are square roots of the average variance extraction (AVE) of each latent variable. The data below the diagonal line is the HTMT value between the latent variables

\section{Build the Model of Factors Influencing Tourists' Word of Mouth in Low-Carbon Eco-Tourism Scenic Spots}

\subsection{Overview of Tourist Attractions.}

Xingwen Shihai is located in Xingwen county, Yibin city, Sichuan province. It is located at the southern edge of Sichuan basin, the junction of Sichuan, Yunnan and Guizhou, belonging to the remaining veins of Wumeng mountain. The county is high in the south and low in the north, with an elevation of 276 meters to 1,795 meters. There are many nationalities living together in the county, mainly the Han nationality. There are 17 ethnic minorities in the county, and the Hmong account for $11 \%$ of the total population. A collection of the world's "three great" karst in a body: the surface of the stone forest landscape, underground caves, and world-class big funnels. Famous landscapes include Tianquan cave, Shilin beauty, Large funnel, Husband and wife peak, Bo people hanging coffin, Tianshi cave, etc.

In April 2017, Sichuan province issued the "13th five-year" tourism development plan for Sichuan province, and Xingwen was included in the list of 18 provincial-level tourism strong counties, requiring accelerating the process of Xingwen Shihai to establish a national " $5 \mathrm{~A}$ " tourism scenic spot. Currently, Shihai scenic spot is carrying out upgrading and renovation work according to the 1,000-point standard of national " $5 \mathrm{~A}$ " scenic spot evaluation. In order to solve the problem of water shortage in karst landforms, the government set up ecological microorganism treatment toilets in the scenic area. At the same time, the construction of transportation should be strengthened to promote the construction of external transportation and drive the development of surrounding scenic spots. We should make full use of the cultural heritage of the scenic spot and expand its cultural industry. We should fully tap tourism resources, improve supporting facilities, and speed up the construction and development of low-carbon eco-tourism in scenic spots.

\subsection{Model Construction.}

Based on Zhang's loyalty model for tourists [15] and the research on Xingwen Shihai, in this paper, from the perspective of food, hospitality, travel, visit, shopping and entertaining, the model of tourist experience degree of low-carbon eco-tourism scenic spot is constructed. And according to the above content, this paper simplifies food, hospitality and travel into two dimensions, and subdivides visit, shopping and entertaining into four dimensions: scenic spot management, natural environment, entertainment and low-carbon operation. Each dimension is described around the construction of low-carbon eco-tourism in the scenic area, as shown in the figure 1 below. 


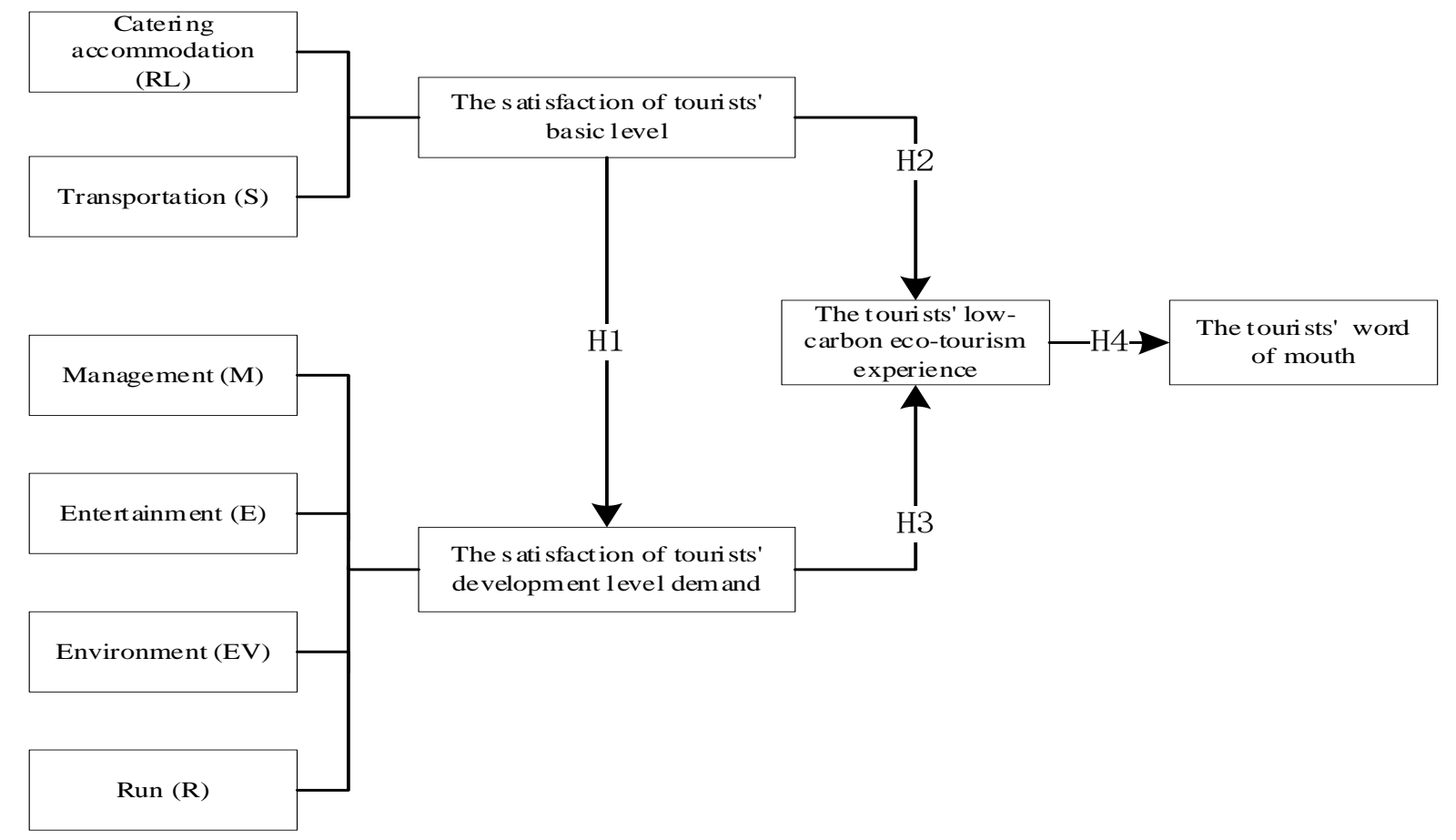

Fig 1. The impact factor model of tourists' word of mouth in low-carbon eco-tourism scenic spots

The data were imported into SmartPls3.0 to verify the "overall model of tourist word of mouth of low-carbon eco-tourism scenic spots", and the following model was obtained.

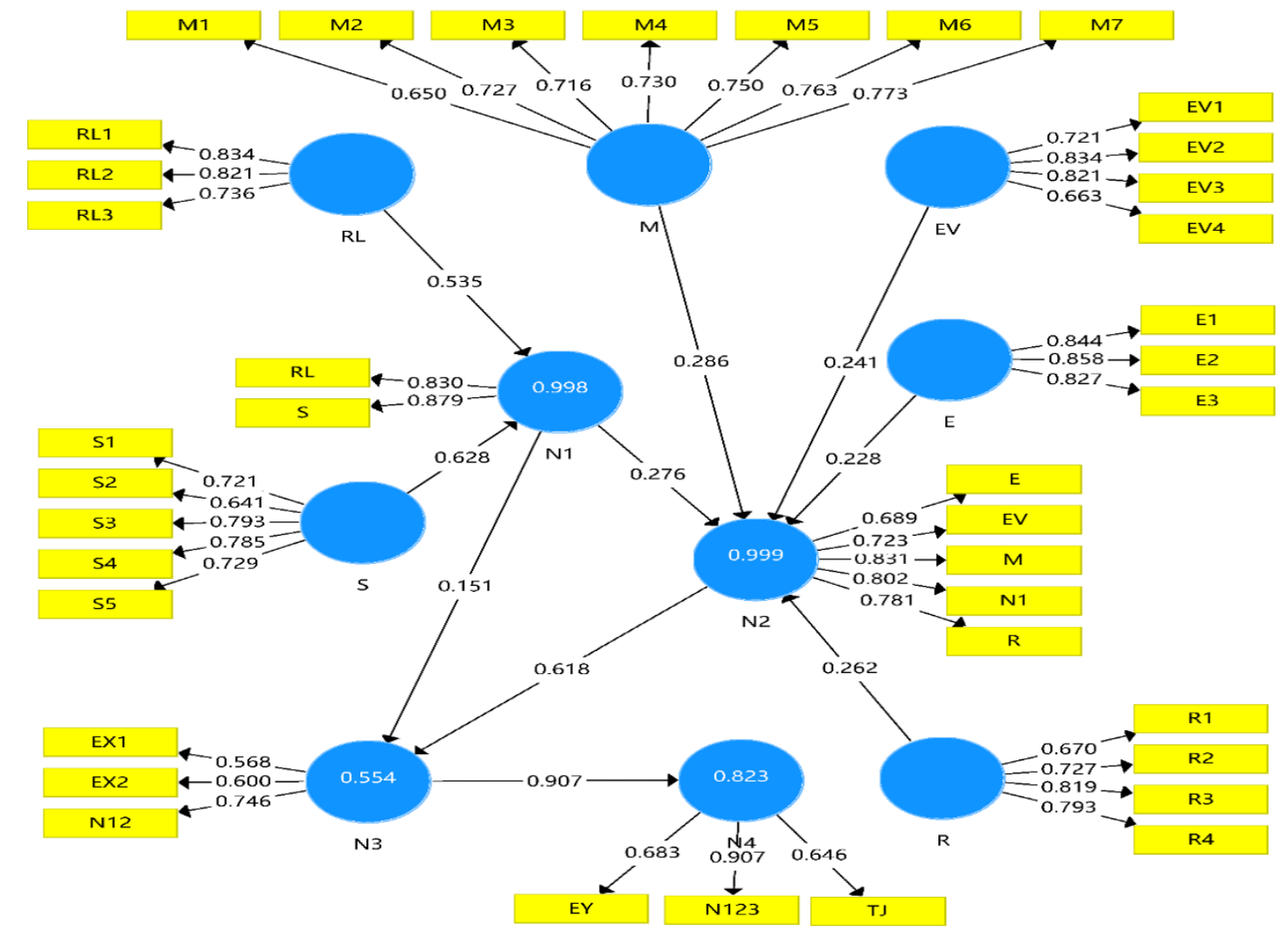

Fig. 2 The overall model of factors influencing tourists' word of mouth in low-carbon eco-tourism scenic spots 
The reliability and validity of the model are tested, except N1 which Cronbach's Alpha value is low because of a small number of projects, but it also reached 0.63 with a certain reliability, the rest of the project variable Cronbach's Alpha $>0.7$, and N1 composite reliability $>0.8$, AVE $>0.5$. The results show that the model has good reliability and convergent validity, which passes the reliability validity test. And the significance analysis of the path coefficients of each latent variable show that $\mathrm{T}$ values are all greater than $6, \mathrm{P}$ values are all less than 0.001 . Therefore, the model passes the significance level test. The detailed results are shown in table 5

Table 5 Construct reliability and validity

\begin{tabular}{llll}
\hline & Cronbach's alpha & CR & AVE \\
\hline E & 0.798 & 0.88 & 0.711 \\
EV & 0.758 & 0.847 & 0.582 \\
M & 0.854 & 0.889 & 0.534 \\
R & 0.745 & 0.84 & 0.569 \\
RL & 0.714 & 0.84 & 0.638 \\
S & 0.786 & 0.854 & 0.541 \\
N1 & 0.633 & 0.844 & 0.731 \\
N2 & 0.824 & 0.877 & 0.588 \\
N3 & 0.791 & 0.905 & 0.827 \\
N4 & 0.749 & 0.889 & 0.799 \\
\hline
\end{tabular}

Table 6 Hypothesis testing

\begin{tabular}{lllllll}
\hline & $\mathrm{O}$ & $\mathrm{M}$ & $\mathrm{STDEV}$ & $\mathrm{T}$ Value & P Value & Result \\
\hline $\mathrm{N} 1$-> N2 & 0.276 & 0.277 & 0.008 & 34.429 & 0 & Supported \\
$\mathrm{N} 1$-> N3 & 0.151 & 0.154 & 0.045 & 3.366 & 0.001 & Supported \\
N2 -> N3 & 0.618 & 0.619 & 0.036 & 16.982 & 0 & Supported \\
N3 -> N4 & 0.907 & 0.907 & 0.006 & 145.664 & 0 & Supported \\
\hline
\end{tabular}

Note: $\mathrm{O}=$ the original sample. $\mathrm{M}=$ sample mean. $\mathrm{STDEV}=$ standard deviation

According to the results, the path coefficient of tourists' basic level demand satisfaction to tourists' development level demand satisfaction is 0.276 , T value is 34.429 and $\mathrm{P}$ value is 0.000 , which pass the significance level test. Therefore, the satisfaction of tourists' basic level demand positively influences the satisfaction of tourists' development level demand. The path coefficient of tourists' basic level demand satisfaction to tourists' low-carbon eco-tourism experience is $0.151, \mathrm{~T}$ value is 3.366 and $\mathrm{P}$ value is 0.001 , which pass the significance level test. Therefore, the tourists' basic level demand satisfaction positively affects tourists' low-carbon eco-tourism experience. The path coefficient of tourists' development level demand satisfaction to tourists' low-carbon eco-tourism experience is 0.618 , $\mathrm{T}$ value is $16.982, \mathrm{P}$ value is 0.000 , which pass the significance level test. Therefore, tourists' development level demand satisfaction positively influences the tourists' low-carbon eco-tourism experience. The path coefficient of tourists' low-carbon eco-tourism experience to the tourists' word of mouth is 0.907 , T value is $145.664, \mathrm{P}$ value is 0.000 , which pass the significance level test. Therefore, the tourists' low-carbon eco-tourism experience positively influences the tourists' word of mouth.

\section{Conclusion}

Through empirical analysis, this paper studies and analyzes the impact factors of tourists' word of mouth on low-carbon eco-tourism in Xingwen Shihai, and verifies that the demand of tourists is not only stratified, but also related to some extent. In the theoretical level, it explains the influence of tourists' demand satisfaction on tourists' experience degree in the low-carbon eco-tourism scenic 
spot, and further influences the tourists' word of mouth through the tourists' experience degree, so as to put forward more targeted countermeasures and suggestions for improving the tourists' word of mouth and promoting the development of the scenic spot.

1) The low-carbon eco-tourism experience of tourists has a significant impact on the tourists' word of mouth (path coefficient $=0.907$ ). Therefore, improving the tourist experience is a major solution to improve the tourists' word of mouth. When improving the tourists' low-carbon eco-tourism experience, the tourists' word of mouth is also generally improved [15].

2) The satisfaction of tourists' demands at the development level has a greater impact on the tourists' experience degree of low-carbon eco-tourism, reaching a height of 0.618 . Therefore, it is of great significance to improve the satisfaction of tourists' demands at the development level, strengthen the management of the scenic area, protect the natural environment, develop entertainment projects and realize the low-carbon operation of the scenic area to promote the economic development of the scenic area [29].

3) The satisfaction of tourists' basic needs is composed of two latent variables, namely, catering accommodation and transportation, and the impact of catering accommodation and transportation on the satisfaction of tourists' basic needs is 0.535 and 0.628 , respectively. In contrast, the impact of transportation on the satisfaction of tourists' basic needs is more profound. Therefore, increasing the traffic management and improving the transportation facilities in the scenic spot, reducing the noise caused by the congestion in the scenic spot, reducing environmental damage and other problems that reduce the satisfaction of tourists can significantly improve the satisfaction of the basic level of tourists within the scenic spot [30].

4) The satisfaction of tourists' demands at the development level is composed of four dimensions: scenic area management, entertainment, natural environment and low-carbon operation, and the four dimensions of scenic area management, entertainment, natural environment and low-carbon operation have almost the same impact on the satisfaction of tourists' demands at the development level, which are $0.228,0.241,0.286$ and 0.262 , respectively. Therefore, the scenic area should pay attention to the coordination and common development of these four aspects when paying attention to meeting the demands of tourists' development level. While playing an entertainment role, the scenic area also needs more management attention to provide diversified education projects and more natural scenic environment [31]. The low-carbon operation of the scenic area plays an important role in creating a more beautiful natural environment of the scenic area. The scenic area creates low-carbon eco-tourism attractions through low-carbon operation, builds low-carbon eco-tourism facilities, provides low-carbon environment for tourists and promotes the low-carbon eco-development of the scenic area [29].

\section{Acknowledgments}

This research was funded by National Natural Science Foundation of China (Grant Nos. 71501019), China's Post-doctoral Science Fund Project (Grant No. 2018M631069), Key Program of Resource-based City Development Research Center (Grant No. ZYZX-ZD-1701), Philosophy and Social Science Planning Program of Chengdu (Grant No. 2018A09), Soft Science Research Program of Chengdu (Grant No. 2017-RK00-00425-ZF) and Special Funding for Post-doctoral Research Project of Sichuan in 2017 Named "Dynamic Evolution of Multi-System Coupling in Resource-Oriented Cities of Western China from Technology Innovation-Driven Perspective”.

\section{References}

[1] P.M. Cox, R.A. Betts, C.D. Jones, S.A. Spall, I.J. Totterdell, Acceleration of global warming due to carbon-cycle feedbacks in a coupled climate model, Nature. 408(2000) 184-7. 
[2] J.D. Figueroa, T. Fout, S. Plasynski, H. Mcilvried, R.D. Srivastava, Advances in CO capture technology-The U.S. Department of Energy's Carbon Sequestration Program, International Journal of Greenhouse Gas Control. 2(2008) 9-20.

[3] P. Friedlingstein, P.M. Cox, R.A. Betts, L. Bopp, W.V. Bloh, V. Brovkin, et al., Climate-carbon cycle feedback analysis: Results from the (CMIP)-M-4 model intercomparison, Journal of Climate. 19(2006) 3337-3353.

[4] J. Zhang, Evaluating regional low-carbon tourism strategies using the fuzzy Delphi-analytic network process approach, Journal of Cleaner Production. 141(2017) 409-419.

[5] C.C. Tang, L.S. Zhong, S.K. Cheng, Study on the connotations and sustainable development strategies on low-carbon tourism in China, Economic Geography. 31(2011) 862-867.

[6] C.B. Wu, C.H. Xie, L.H. Wang, A model and an empirical analysis of tourist word-of-mouth communication based on tourism experience and host-guest relationship-take tourists to Dalian as an example, Systems Engineering. 31(2013) 81-86.

[7] C.B. Wu, S.S. Zhang, Impact of tourist's negative word of mouth on the tourism image of coastal city of Dalian: text analysis based on comments from tourists network, Ocean Development and Management. 35(2018) 101-106.

[8] L. Sangjae, J. Sungil, K. Doyoung, The impact of tour quality and tourist satisfaction on tourist loyalty: the case of Chinese tourists in Korea, Tourism Management. 32(2011) 1115-1124.

[9] H.M. Zhang, X.X. Fu, L.A. Cai, L. Lu, Destination image and tourist loyalty: a meta-analysis, Tourism Management 40(2014) 213-223.

[10] Q. Zhu, Research on the influence of destination image on tourists' intention to revisit, Hunan Normal University, 2011.

[11] S.J. Backman, J.L. Crompton, The usefulness of selected variables for predicting, activity loyalty, Leisure Science. 13(1991) 205-220.

[12] C.C. Frangos, D. Karapistolis, G. Stalidis, F. Constantinos, I. Sotiropoulos, I. Manolopoulos, Tourist loyalty is all about prices, culture and the sun: a multinomial logistic regression of tourists visiting Athens, Procedia-Social and Behavioral Sciences. 175(2015) 32-38.

[13] X. Chen, Research on the relationship between customer satisfaction and positive word-of-mouth, South China university of technology, 2011.

[14] S. Wijaya, B. King, T.H. Nguyen, A. Morrison, International visitor dining experiences: a conceptual framework, Journal of Hospitality \& Tourism Management. 20(2013) 34-42.

[15] J. Pearce, R. Dowling, Monitoring the quality of the visitor experience: an evolutionary journey, Journal of Outdoor Recreation \& Tourism. Article in Press, 2018.

[16] Z.F. Chen, W.F. Guo, The influence of tourist experience and consumption emotion on tourist citizenship behavior, Journal of Lanzhou University of Finance and Economics. 4(2016) 77-85.

[17] B.J. Pine, J.H. Gilmore, The experience economy: past, present and future, Handbook on the Experience Economy, 2015.

[18] E. Cohen, A phenomenology of tourist experiences, Sociology. 13(1979) 179-201.

[19] Y.L. Chen, Study on tourists' satisfaction of film and television theme parks based on tourism experience, Zhejiang university, 2007.

[20] Y.J. Xie, Basic tourism studies, 3rd edition, China tourism press, 2011.

[21] M. Pan, L.Z. Zhou, M. Zhang, An investigation on Leshan leisure tourism based on tourists' experience, Journal of Green Science and Technology. 10(2014) 304-305.

[22] A.H. Maslow, A theory of human motivation, Psychological Review. 50(1943) 370-396.

[23] A. Pizam, Y. Neumann, Dimensions of tourist satisfaction with a destination area, Annals of Tourism Research. 5(1978) 314-322.

[24] T.H. Lian, C.H. Yu, X.J. Bao, S. Lu, Research on the satisfaction of theme park visitors based on fuzzy comprehension evaluation: a case study in Wuhu fantawild adventure, Resources Science. 34(2012) 973-980.

[25] W.Y. Yu, Y.F. Feng, J.M. Liang, Hakka culture tourism development based on tourist satisfaction, Scientia Geographica Sinica. 33(2013) 824-830.

[26] R.G. Zhang, Z.X. Liao, Y.Y. Luo, Study on the relationship between the stratification of tourists' demand factors and satisfaction based on SEM-a case study of Jiuzhaigou scenic spot, Journal of Southwest Minzu University (Humanities and Social Science). 33(2012) 142-146.

[27] Q. Wan, H.B. Sun, Research on satisfaction of tourist based on structural equation model-a case study in Kunming, Journal of Qufu Normal University (Natural Science). 2(2015) 67-73.

[28] J. Henseler, C.M. Ringle, M. Sarstedt, A new criterion for assessing discriminant validity in variance-based structural equation modeling, Journal of the Academy of Marketing Science. 43(2015) 115-135.

[29] C. Meng, Y.M. Wang, Low-carbon tourism: a new mode of tourism development, Tourism Tribune. 25(2010) 13-17. [30] R.M.W. Rathnayake, How does “crowding” affect visitor satisfaction at the Horton Plains National Park in Sri Lanka, Tourism Management Perspectives. 16(2015) 129-138. 
[31] H.S. Lee, Measurement of visitors' satisfaction with public zoos in Korea using importance-performance analysis, Tourism Management. 47(2015) 251-260. 